\title{
The asymmetry of income distribution between stakeholders within the framework of industrial park structures
}

\author{
Andrey Plakhin ${ }^{1 *}$, Igor Semenets ${ }^{2}$, and Ekaterina Ogorodnikova ${ }^{1}$ \\ ${ }^{1}$ Ural State University of Economics, Department of Management, 8th March str. 62, Ekaterinburg, Russian Federation \\ ${ }^{2}$ Slavonic University of the Republic of Moldova, Department of Economics, Florilor str. 28/1, Chisinau, Moldova
}

\begin{abstract}
The purpose of this article is to prove the author's hypothesis about the formation of an asymmetry in the distribution of income of stakeholders in the industrial park structure, due to the increased impact of economies of scale on the activities of the residents of the park. In this article, the authors propose a model of income distribution, on the basis of which the prevailing role of the state as the beneficiary of the results of activity within the framework of the park structure was proved. It also indicates a clear asymmetry of income distribution, formed due to economies of scale between other stakeholders. The revealed characteristics can be claimed for the justification of concepts and other documents of a program nature in the formation of industrial park structures.
\end{abstract}

\section{Introduction}

The modern vector of the development of the Russian economy is largely based on the formation of mesoeconomic objects that have a common infrastructural base. The objects of the meso-level include new park structures for the Russian economy. The works of M. Mădălina, P.A. Constantin [1], M. Mani, S.M. Hosseini, T. Ramayah [2], I. Siskos and L.N. Van Wassenhove [3], A.E. Plakhin, E.S. Ogorodnikova [4], [5] present a detailed description of the park structures. Clusters, new industrial areas, special economic zones and other territorial localization of industrial production, which can be called the unifying category "industrial park structure" [5].

The effectiveness of the use of industrial parks structures in the world is confirmed quantitatively. There are more than 400 industrial parks in the USA, 200 parks in Germany, 200 parks in Germany, 262 in Turkey, 140 in the Czech Republic, over 70 in Japan, more than 60 in Poland, 34 in Slovakia, 14 in Costa Rica, in Romania - 9. Vietnam has created about 200 parks, which account for $25 \%$ of GDP and $40 \%$ of attracted investments [6]. About 400 industrial parks have been created in China over the past 40-50 years.

The experience of creating parks in different countries has shown that this is the most understandable, profitable and therefore popular with the investor product. 444 industrial parks have been created in the regions of Russia [7], which is comparable to countries such as China and the United States, but their effectiveness is still far from the industrial parks of these countries.

But features of the park structure make it ineffective to apply a wide range of methods of administrative management. In the authors' opinion, the processes of managing the development of mesoeconomy objects largely depend on indirect regulatory instruments, the integrated application of which relates to the stakeholder approach to management. This methodology makes it possible to take into account the specific features of the interests of groups of persons participating in activities and using their own criteria for assessing the functioning of the park structure from the point of view of its own interests. Several authors have proposed a step-by-step mechanism for analyzing relationships with stakeholders [8], [9], [10], [11].

R.S. Gondarev and N.V. Raznov believe that the most advanced way to interact with stakeholders today is bridging, which implies strategic partnership and pooling of resources [12]. However, these same authors point to the difficulties in organizing interaction between the parties.

R.W. Nuzhdin and A.N. Polozov see the main goal of stakeholder management in achieving positive synergy. They believe that if synergy is expressed in increasing the added value and profitability of the parties involved, it means that the cost is added for integration when the possibilities of economic potentials are used as efficiently as possible [13].

A.M. Hein, M. Jankovic, W. Feng and others adapt the stakeholder value network approach from the strategic management literature to the industrial symbiosis context as a means to provide insights into the power of stakeholders of an industrial symbiosis [14].

Some authors emphasize the digital accompaniment of the stakeholder approach to managing complex systems. In particular M. Neubauer and C. Stary present several case studies highlighting the latest findings in Industry 4.0 projects utilizing S-BPM features. They provides a realistic portrait of the status quo based on current

\footnotetext{
* Corresponding author: apla@usue.ru
} 
findings, and outlines the future activities to be pursued in order to establish stakeholder-centred digital production systems [15].

S. Ismulyati and G. Ginting offer conceptual modeling to clarify more deeply in how connection formed by building relationship with primary stakeholder can support open innovation through co-innovating and co-creating value [16].

A review of the literature sources showed that the issues of stakeholder participation in the implementation of joint projects, as well as the distribution of revenues from their implementation to all stakeholders, are still relatively insufficiently studied.

\section{Methods}

In several works mentioned above, one can note the manifestation of the category of "added value", which combines the use of the stakeholder approach and industrial park structures, the creation of which is aimed at obtaining external effects, including synergies.

This conclusion allows us to talk about the effectiveness of economic methods of managing the park structure, which can include mechanisms for the distribution of income or additional "added value", formed due to external effects. The distribution tools help to stimulate certain areas, primarily the development of human capital and regional infrastructure. Such tools will correspond to the adaptation principles of the stakeholder approach, which considers development through the prism of satisfying the multidirectional interests of multiple groups of influence.
To understand the subject, research authors proposed the concept of "asymmetry" reflecting the uneven distribution of income. Objects of control can be both alignment of "asymmetry" and its artificial formation. In the first case, it is possible to use the methods of institutional regulation, by creating transfer funds that redistribute income between stakeholders. In the second case, the "asymmetry" of income distribution can be an economic lever to stimulate the creation of individual infrastructure facilities, or to implement the necessary functions within the framework of the park structure.

To solve this scientific problem, the authors formed a model of income distribution among the stakeholders of the park structure (Fig. 1).

In this model, the main stakeholders of the park structure and the types of income they receive are listed. It should be noted that some of the influence groups receive income not directly, but with the mediation of direct participants in the operational process. For example, the state that regulates the distribution of tax revenues forms many aspects of the activity of the park structure.

Using this model, the initiators of the creation of an industrial park structure can justify the effectiveness of the project, attract investors and receive the appropriate support of the state as the most interested participant and the largest beneficiary.

Individual participants in turn can also see the full picture of effects taking into account the asymmetry of income distribution from joint activity.

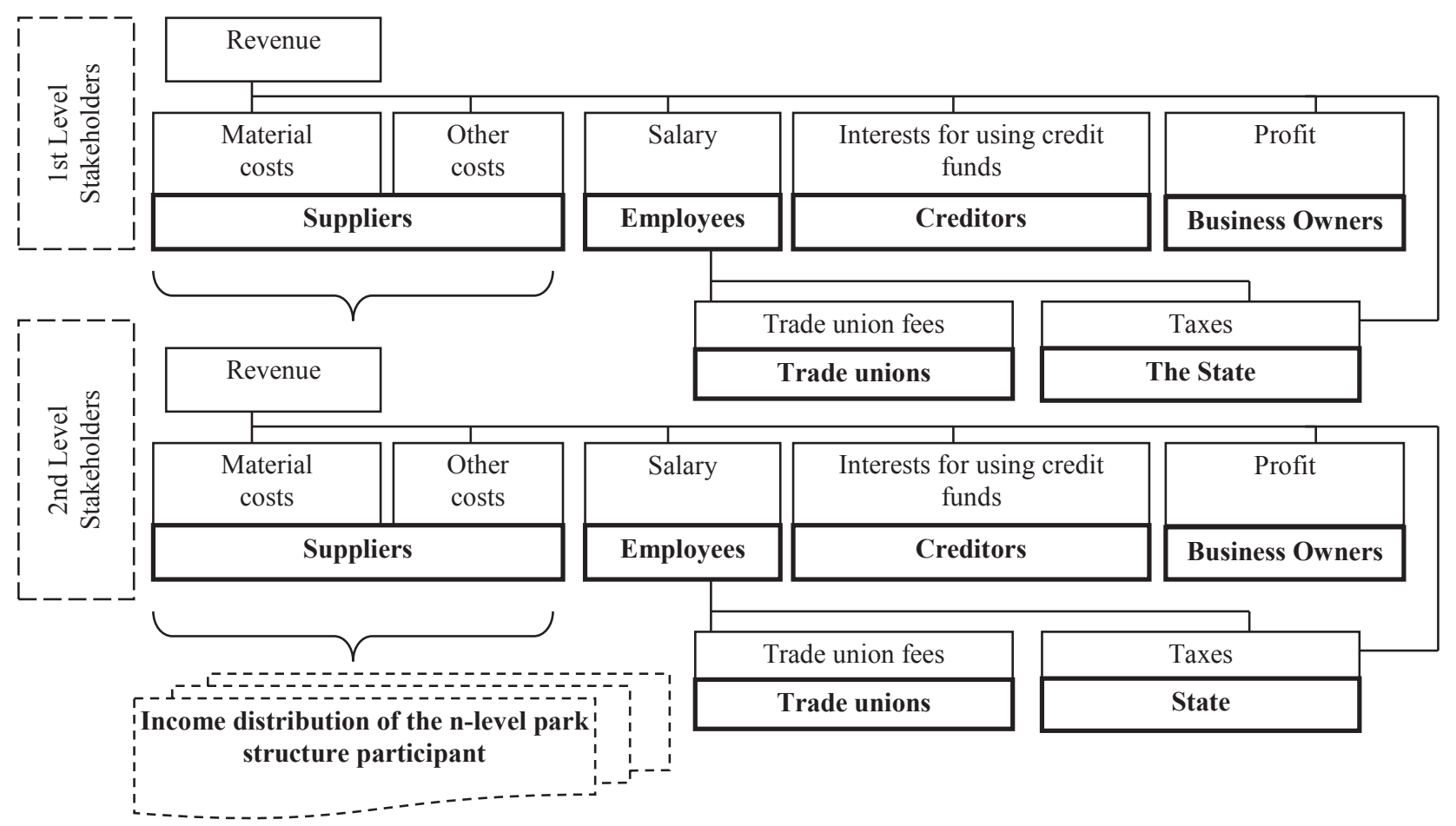

Fig. 1. Model of income distribution among stakeholders of the park structure 


\section{Results}

As an object of research, this article selects the industrial park "Grabtsevo", the development of which is carried out in the Kaluga region of Russian Federation within the project "Development of the infrastructure of industrial parks: the formation of a cluster of production of cars and auto components".

The project also includes industrial parks "Rosva" and "Kaluga-Yug". It is in these parks that a large number of auto cluster enterprises are concentrated. At the same time, large pharmaceutical manufacturers also preferred the site in "Grabtsevo".

As of the beginning of 2016, 12 industrial parks operate in the Kaluga region, the total area of which is 7,556.5 hectares. In territory of industrial parks in aggregate carry out the activity of 94 companies-residents.

It should be noted that in recent years, the Kaluga region among the subjects of the Russian Federation demonstrates a stable growth dynamics in all important economic indicators. Large-scale modernization of the regional economy, a significant increase in labor productivity, the use of advanced production technologies and, finally, the active attraction of investments - such, according to experts, are its components of successful social and economic development. An effective system of working with investors has been created in the region. Competitive advantages among Russian regions are not only favorable geographical position and proximity to the huge capital market, but also low risks of investment, provision of tax incentives and subsidies, competitive tariffs for natural monopolies, administrative support from the state authorities of the region [17].

The analysis of the distribution of tax and customs revenues according to levels of the budgetary system indicates their disproportionality. The regional level receives only a small part of its huge investments in the creation of parks in the form of tax revenues. On average, from one ruble of costs incurred, the regional budget has returned 1.35 rubles, that is, after almost a decade, the region has reached the self-sustainability of these projects. As for the overall economic efficiency, more optimistic results are obtained here. On average, one ruble of expenses had 12.5 rubles of profit. The greatest value has a multiplier effect in the park "Grabtsevo" - 24.76 rubles. The lowest figure is observed in the park "Rosva" - 4.45 rubles [18].

Table 1 shows the dynamics of commissioning of production facilities located in the park.

As can be seen from the Table 1 on the territory of the park structure manufacturing enterprises of related activities are located, therefore, the principles of the park structure formation are observed and the object corresponds to the research objectives.
Table 1. Commissioning of the main production capacities of the industrial park "Grabtsevo"

\begin{tabular}{|c|c|c|}
\hline Name of resident & \begin{tabular}{|c|} 
Commissioning \\
year
\end{tabular} & Activity type \\
\hline \multirow{2}{*}{$\begin{array}{l}\text { Volkswagen } \\
\text { Group Rus LLC }\end{array}$} & 2015 & $\begin{array}{c}\text { manufacture of internal } \\
\text { combustion engines for cars }\end{array}$ \\
\hline & 2007 & cars production \\
\hline $\begin{array}{c}\text { Gestamp- } \\
\text { Severstal-Kaluga } \\
\text { LLC }\end{array}$ & 2010 & $\begin{array}{l}\text { manufacture of stamped parts } \\
\text { for car bodies }\end{array}$ \\
\hline $\begin{array}{c}\text { Benteleer } \\
\text { Automotive LLC }\end{array}$ & 2010 & $\begin{array}{l}\text { manufacture of car suspension } \\
\text { parts }\end{array}$ \\
\hline $\begin{array}{c}\text { Raidel Automotive } \\
\text { Rus LLC } \\
\end{array}$ & 2010 & $\begin{array}{c}\text { manufacture of carpets for car } \\
\text { doors }\end{array}$ \\
\hline $\begin{array}{c}\text { Yapp Rus } \\
\text { Automotive } \\
\text { Systems LLC } \\
\end{array}$ & 2011 & production of plastic fuel tanks \\
\hline $\begin{array}{l}\text { FUIAO Glass Rus } \\
\text { LLC }\end{array}$ & 2013 & $\begin{array}{c}\text { manufacture of automobile } \\
\text { glasses }\end{array}$ \\
\hline \multirow[b]{2}{*}{$\begin{array}{l}\text { Branch of JSC } \\
\text { "Magna } \\
\text { Automotive Rus" }\end{array}$} & 2010 & $\begin{array}{l}\text { production and painting of car } \\
\text { bumpers }\end{array}$ \\
\hline & 2016 & $\begin{array}{l}\text { construction of the second stage } \\
\text { of production facilities and } \\
\text { infrastructure of the plant for the } \\
\text { production of auto parts }\end{array}$ \\
\hline
\end{tabular}

It is important to note that the project of the Volkswagen concern in the industrial park Grabtsevo in Kaluga has become one of the largest not only in the Kaluga region, but also in Russia. For the German company, other major automakers with a worldwide name came to the region Volvo Trucks (a plant was built in the industrial park Kaluga-Yug), PSA Peugeot Citroen Mitsubishi (the assembly plant is located in the industrial park Rosva). In the course of the study, information was collected and summarized on the distribution of income among the main groups of stakeholders in the industrial park "Grabtsevo" (Fig. 2) [19].

As can be seen in the figure, the largest beneficiary of the project is the state, since a little less than half of the generated income goes to different levels of the budget. The collected funds go to the public sector and are channelled into the formation of the social environment and infrastructure of the region.

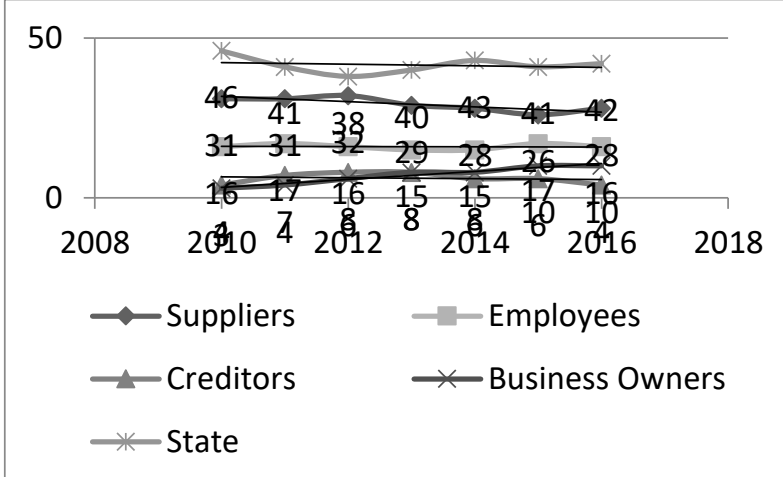

Fig. 2. Asymmetry distribution of income of stakeholders in the industrial park "Grabtsevo" 2010-2016, \% 


\section{Discussions and Conclusions}

Asymmetric dynamics is observed in the distribution of the additional effect when new park capacities are introduced. There is a decrease in the share of material costs, which is due to the effects of cooperation among participants in the industrial park and the share of creditors, showing a decrease in dependence on borrowed capital. If we consider the income of employees, then no significant changes in the structure of income distribution are observed. This fact is an example of the asymmetry of income distribution, the correction of which is possible by creating equalizing or incentive funds in the park. In particular, it is possible to propose the creation of educational centres, for example, a corporate university for the automotive industry.

Such a project will allow to direct additional "added value" to improve the quality of human capital of industrial park enterprises and ultimately significantly improve the efficiency of its work.

\section{References}

1. M. Mădălina, P.A. Constantin, Industrial parks and business incubators as clustering incipient forms, Quality - Access to Success 18, 304-307 (2017).

2. M. Mani, S.M. Hosseini, T. Ramayah, Parks as business opportunities and development strategies, Business Strategy Series 13 (2), 96-101 (2012).

3. I. Siskos, L.N. Van Wassenhove, Synergy Management Services Companies: A New Business Model for Industrial Park Operators, Journal of Industrial Ecology 21 (4), 802-814 (2017).

4. A.E. Plakhin, E.S. Ogorodnikova, I.G. Generalov, Institutional conditions for the creation and methodological aspects of assessing the effectiveness of clusters: Russian and foreign experience, Azimuth of scientific research: economics and management 2 (19), vol. 6, 61-65 (2017).

5. A.E. Plakhin, Strategic management for the development of industrial park structures of cluster type: monograph, M: INFRA-M, 218 (2017).

6. O.N. Belenov, Yu.V. Shurchkova, T.Yu. Smolyaninova, Industrial parks in Russia and abroad: the experience of creation and development, Modern economics: problems and solutions 7, 78-92 (2014).

7. Association of Industrial Parks (official site), industry review "Industrial parks of Russia", issue 4, (2016), available at: http://www.indparks.ru/ (accessed 04/06/2018).
8. V.O. Morozov, Determination of the strategic positions of the stakeholder-organization, Territory of new opportunities. Bulletin of the Vladivostok State University of Economics and Service 1 (19), 138-14 (2013).

9. E.K. Timofeeva, Corporate Social Responsibility: Sustainable Development and Interaction with Stakeholders, Ethnosociology and Interethnic Culture 4 (82), 44-49 (2015).

10. I.N. Tkachenko, Application of the methodology of corporate governance for the analysis of stakeholders in public-private partnership projects, Administrative Sciences in Modern Russia 1, vol. 1, 40-44 (2014).

11. I.N. Tkachenko, K.K. Sivokoz, Usage of AGILE and SCRUM flexible technologies to manage project stakeholders, Manager 4, 85-95 (2017).

12. R.S. Gondarev, N.V. Raznova, Building a Business Development Model Based on Integration of the Organizational Changes Concept and Stakeholder Management Tools, Economics and Management in the 21st Century: Development Trends 14, 7-15 (2014).

13. R.V. Nuzhdin, A.N. Polozova, Business analysis of the opportunities of stakeholder-management in achieving positive synergy, Bulletin of the Voronezh State University of Engineering Technologies 4 (70), 437-445 (2016).

14. A.M. Hein, M. Jankovic, W. Feng and others, Stakeholder power in industrial symbioses: A stakeholder value network approach, Journal of Cleaner Production 148, 923-933 (2017).

15. M. Neubauer, C. Stary, S-BPM in the Production Industry: A Stakeholder Approach, 1-232 (2016).

16. S. Ismulyati, G. Ginting, Encouraging open innovation with open sources development for small medium industries (smis) productivity: Stakeholder approach, International Journal of Applied Business and Economic Research 13 (7), 5535-5548 (2015).

17. A.D. Artamonov, Investments and innovations - the basis of the future of the Kaluga region, Economics and Management 12, 99-103 (2010).

18. T.A. Burtseva, A.A. Saveliev, Performance of creation of industrial parks in the regions of Russia, Regional economy and management: electronic scientific journal 1-2 (49), 234-244 (2017).

19. The system of professional analysis of markets and companies "Spark-Interfax". Available at: http://www.spark-interfax.ru/ (accessed 04/06/2018). 